Check for updates

Cite this: Environ. Sci.: Processes Impacts, 2021, 23, 188

DOI: $10.1039 / \mathrm{d} 0 \mathrm{em} 90043 \mathrm{e}$

rsc.li/espi

\section{Correction: Emerging per- and polyfluoroalkyl substances (PFAS) in human milk from Sweden and China}

\author{
Raed Awad, ${ }^{\text {ab }}$ Yihui Zhou, ${ }^{c}$ Elisabeth Nyberg, ${ }^{d}$ Shahla Namazkar, ${ }^{a}$ Wu Yongning, ${ }^{e}$ \\ Qianfen Xiao, ${ }^{c}$ Yaije Sun, ${ }^{f}$ Zhiliang Zhu, ${ }^{,}$Åke Bergman ${ }^{\text {acg }}$ and Jonathan P. Benskin*a
}

Correction for 'Emerging per- and polyfluoroalkyl substances (PFAS) in human milk from Sweden and China' by Raed Awad et al., Environ. Sci.: Processes Impacts, 2020, 22, 2023-2030, DOI: 10.1039/D0EM00077A.

On September $17^{\text {th }}, 2020$, the European Food Safety Authority (EFSA) established a tolerable weekly intake (TWI) of $4.4 \mathrm{ng}$ per kg body weight (bw) per week based on the sum concentrations of perfluorooctanoate (PFOA), perfluorononanoate (PFNA), perfluorohexane sulfonate (PFHxS), and perfluorooctane sulfonate (PFOS). ${ }^{1}$ Following review of the EFSA opinion, we identified two areas for correction in our recently published article on occurrence of emerging per- and polyfluoroalkyl substances (PFAS) in human breast milk from China and Sweden. ${ }^{2}$ Firstly, we calculated estimated weekly intakes (EWIs) for PFAS in breast milk from Sweden and China and compared these values to the TWI in the draft EFSA Opinion (8 ng per kg bw per week) ${ }^{3}$ which was higher than the value set in the final EFSA Opinion (4.4 ng per kg bw per week). ${ }^{1}$ More importantly, however, is that comparing EWIs to either TWI appears to have been inappropriate because, according to EFSA, "the exposure of infants from breastfeeding is already taken into account in the derivation of the TWI, so the risk for the breastfed infant should be evaluated by assessing the long-term exceedance of the TWI by the mothers rather than comparing the exposure of infants with the TWI" ${ }^{3}$ While this correction does not impact the conclusions of our study, we acknowledge that it was inappropriate to compare our EWIs to the recent TWIs set by EFSA.

The Royal Society of Chemistry apologises for these errors and any consequent inconvenience to authors and readers.

\title{
References
}

1 EFSA CONTAM Panel(EFSA Panel on Contaminants in the Food Chain), D. Schrenk, M. Bignami, L. Bodin, J. K. Chipman, J. del Mazo, B. Grasl-Kraupp, C. Hogstrand, L. R. Hoogenboom, J.-C. Leblanc, C. S. Nebbia, E. Nielsen, E. Ntzani, A. Petersen, S. Sand, C. Vleminckx, H. Wallace, L. Barregård, S. Ceccatelli, J.-P. Cravedi, T. I. Halldorsson, L. S. Haug, N. Johansson, H. K. Knutsen, M. Rose, A.-C. Roudot, H. Van Loveren, G. Vollmer, K. Mackay, F. Riolo and T. Schwerdtle, Scientific Opinion on the risk to human health related to the presence of perfluoroalkyl substances in food, EFSA J., 2020, 18(9), 6223, DOI: 10.2903/j.efsa.2020.6223.

2 R. Awad, Y. Zhou, E. Nyberg, S. Namazkar, W. Yongning, Q. Xiao, Y. Sun, Z. Zhu, Å. Bergmann and J. P. Benskin, Emerging per- and polyfluoroalkyl substances (PFAS) in human milk from Sweden and China, Environ. Sci.: Processes Impacts, 2020, 22, 2023-2030, DOI: 10.1039/d0em00077a.

3 EFSA CONTAM Panel (EFSA Panel on Contaminants in the Food Chain), D. Schrenk, M. Bignami, L. Bodin, J. K. Chipman, J. del Mazo, B. Grasl-Kraupp, C. Hogstrand, L. R. Hoogenboom, J.-C. Leblanc, C. S. Nebbia, E. Nielsen, E. Ntzani, A. Petersen, S. Sand, C. Vleminckx, H. Wallace, L. Barregård, J.-P. Cravedi, T. I. Haldorsson, L. S. Haug, N. Johansson, H. K. Knutsen, M. Rose, A.-C. Roudot, H. van Loveren, G. Vollmer, K. Mackay, F. Riolo and T. Schwerdtle, Draft Scientific opinion on the risk for human health related to the presence of perfluoroalkyl substances in food, August 31, 2020, accessed from: https://www.efsa.europa.eu/sites/ default/files/consultation/consultation/PFAS_Draft_Opinion_for_public_consultation_Part_I.pdf.

${ }^{a}$ Department of Environmental Science (ACES), Stockholm University, 10691 Stockholm, Sweden. E-mail: Raed.Awad@ivl.se; Jon.Benskin@aces.su.se ${ }^{b}$ Swedish Environmental Research Institute (IVL), 11428 Stockholm, Sweden

${ }^{c}$ State Key Laboratory of Pollution Control and Resource Reuse, College of Environmental Science and Engineering, Tongji University, Shanghai 200092, China ${ }^{d}$ Department of Contaminants, Swedish Environmental Protection Agency, Virkesvägen 2, SE-106 48 Stockholm, Sweden

${ }^{e}$ NHC Key Laboratory of Food Safety Risk Assessment, China National Center for Food Safety Risk Assessment, Beijing, 100021, China

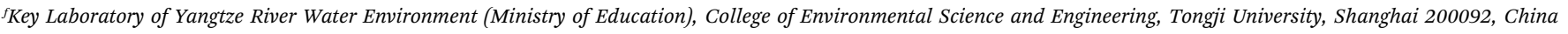
${ }^{g}$ Department of Science and Technology, Örebro University, 70182 Örebro, Sweden 